\title{
Nrf2: a main responsive element in cells to mycotoxin-induced toxicity
}

\author{
Marta Justyna Kozieł ${ }^{1}$ (D) Karolina Kowalska ${ }^{1}$ [D $\cdot$ Agnieszka Wanda Piastowska-Ciesielska' ${ }^{1}$
}

Received: 4 December 2020 / Accepted: 28 January 2021 / Published online: 8 February 2021

(c) The Author(s) 2021

\begin{abstract}
Nuclear factor erythroid 2-like 2 (Nrf2) is a transcription factor participating in response to cellular oxidative stress to maintain the redox balance. Generation of reactive oxygen species (ROS) and, in consequence, oxidative stress, are physiological as well as pathological processes which take place in almost all types of cells. Nrf2, in response to oxidative stress, activates expression and production of antioxidant enzymes to remove free radicals. However, the role of Nrf2 seems to be more sophisticated and its increased expression observed in cancer cells allows to draw a conclusion that its role is tissue-and condition-dependent. Interestingly, Nrf2 might also play a crucial role in response to environmental factors like mycotoxins. Thus, the aim of the study is to review the role of Nrf2 in cells exposed to most common mycotoxins to check if the Nrf2 signaling pathway serves as the main response element to mycotoxin-induced oxidative stress in human and animal cells and if it can be a target of detoxifying agents.
\end{abstract}

Keywords Mycotoxins $\cdot$ Nrf2 $\cdot$ Oxidative stress $\cdot$ Antioxidants

\section{Introduction}

Exposure of human and animals to environmental pollutants: drugs, food additives, pesticides, toxins, ionizing and ultraviolet radiation contributes to formation of high-energy molecules: reactive oxygen species (ROS) and, in consequence, to oxidative stress. Physiological levels of ROS are necessary in cells to assure normal proliferation and growth, signal transduction as well as activation of antioxidants and anti-apoptotic signals (Banerjee et al. 2020). On the other hand, high levels of ROS lead to disturbed homeostasis and may damage cellular components (Rahal et al. 2014). Thus, a balance between ROS levels and activity of detoxifying enzymes is crucial in maintaining health. Cells are able to defend themselves against stressful conditions

Marta Justyna Kozieł and Karolina Kowalska contributed equally.

Agnieszka Wanda Piastowska-Ciesielska

agnieszka.piastowska@umed.lodz.pl

Marta Justyna Kozieł

marta.koziel@umed.lodz.pl

Karolina Kowalska

karolina.kowalska1@umed.lodz.pl

1 Medical University of Lodz, Department of Cell Cultures and Genomic Analysis, Zeligowskiego 7/9, 90-752 Lodz, Poland using a variety of mechanism. The basic one is synthesis and activation of antioxidant enzymes. The nuclear erythroid 2-related factor (Nrf2) plays a significant role in response to oxidative stress (Enomoto et al. 2001; McMahon et al. 2001; Aoki et al. 2001). It was observed that Nrf2-knockout mice $\left(\mathrm{Nrf}^{-/-}\right)$are more sensitive to ROS than wild type mice (Loboda et al. 2017b). The Nrf2 gene (Nfe2l2) in humans is located in locus $2 \mathrm{q} 31.2$. The protein product of this gene belongs to the cap'n' collar subfamily and its mass is about $60 \mathrm{kDa}$. According to the UniProtKB database, this gene is expressed in various tissues and its highest expression is observed in muscle, kidney, lung and liver. $N f e 2 l 2$ may be regulated on different levels: transcriptional, post-transcriptional and via epigenetic modifications. At the transcription level, Nrf2 expression is regulated by the aryl hydrocarbon receptor (AhR), nuclear factor kappa-light-chain-enhancer of activated B cells (NF-KB) and by the $N r f 2$ gene itself (Kwak et al. 2002; Miao et al. 2005; Rushworth et al. 2012). It is believed that Nrf2 expression is also regulated at the epigenetic level (DNA methylation, histone modifications, miRNA) (Guo et al. 2015; Cheng et al. 2016) but this process seems to be very complex and needs to be more elucidated.

Nrf2 consists of seven homology domains (Neh1-7), called Nrf2-ECH (Neh) domains (Hayes and DinkovaKostova 2014) (Fig. 1). All of them play an important 

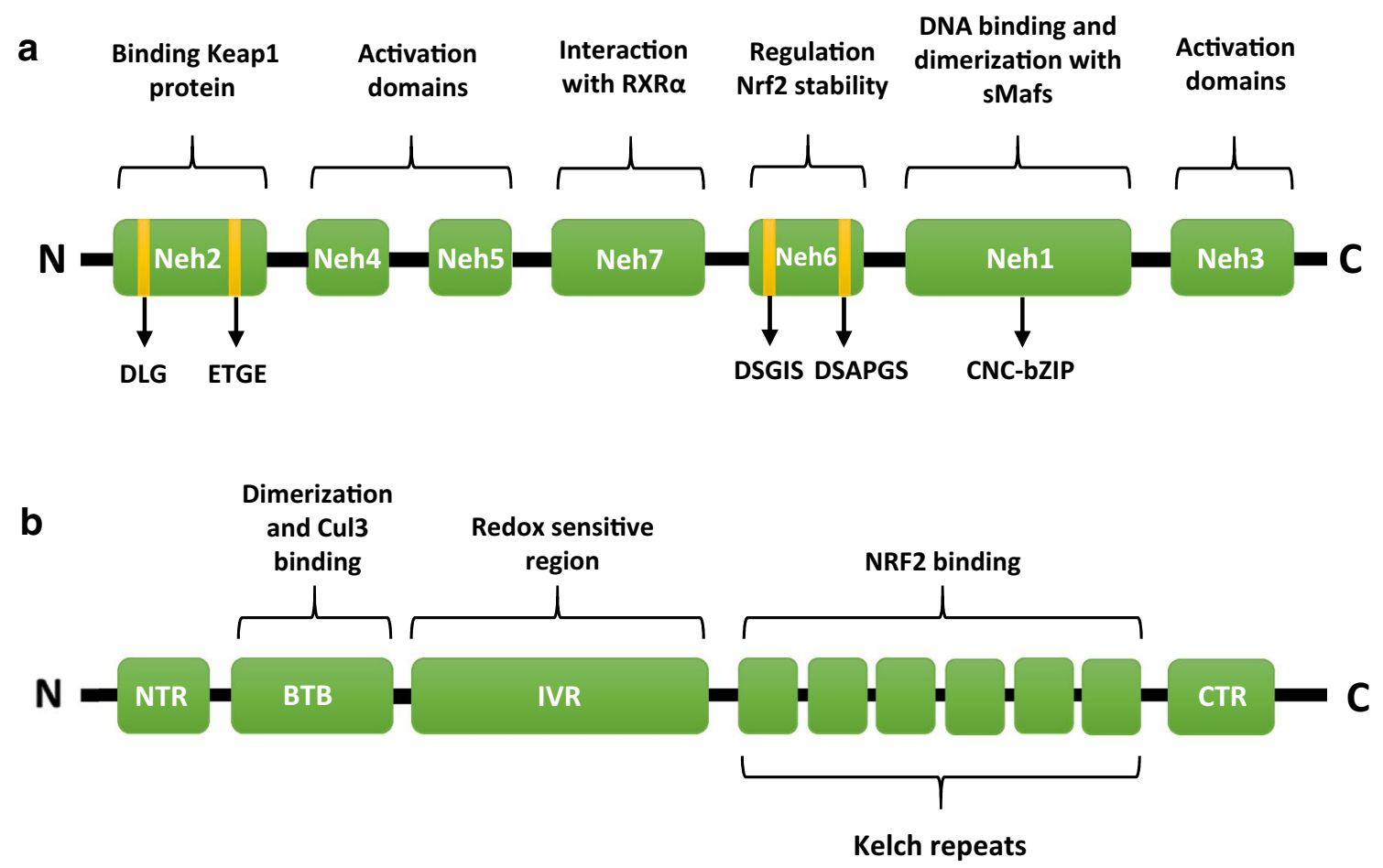

Fig. 1 Structure of the Nrf2 protein (a) and Keap1 protein (b). Keap1 Kelch-like ECH associating protein $1, R X R \alpha$ retinoid $\mathrm{X}$ receptor, $s M a f$ small musculoaponeurotic fibrosarcoma proteins, CNC-bZIP

role in the function of Nrf2: the Neh1 domain contains the Cap 'n'Collar (CNC)-bZIP region which is responsible for dimerization with small Maf (sMAF) proteins and DNA binding (Hirotsu et al. 2012). sMAF proteins heterodimerized by Nrf2 are: MafF, MafG and MafK (Motohashi et al. 2002). The Neh2 domain contains two motifs: DLG and ETGE through which it controls interaction with Keap1 protein (Tong et al. 2006). The Neh3 region is considered responsible for recruitment of chromo-ATPase/helicase DNA-binding protein (CHD) 6 (Hayes and Dinkova-Kostova 2014). The Neh4 and Neh5 regions recruit cAMP response element-binding protein (CREB)-binding protein (CBP) and interact with RAC3 (receptor-associated coactivator 3) (Kim et al. 2013). The Neh6 region contains two peptide motifs: DSGIS and DSAPGS, which are necessary to interact with $\operatorname{TrCP}$ ( $\beta$-transducin repeat-containing protein). After phosphorylation of the DSGIS motif by glycogen synt-

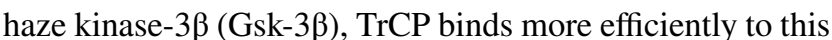
domain and promotes proteasomal degradation of Nrf2 via Skp1-Cul1-F-box (SCF) ubiquitin ligase complex (Tonelli et al. 2018). And the last domain of Nrf2, i.e., Neh7 interacts with the retinoid $\mathrm{X}$ receptor $(\mathrm{RXR} \alpha)$ and thus mediates the repression of transcriptional activity of Nrf2 (Wang et al. 2013). Interestingly, regulation of the Nrf2 transcriptional factor may have therapeutic applications in many diseases. However, it is worth emphasizing that a lot of these
Cap 'n'Collar-basic leucine zipper region, $\mathrm{Cul3}$ Cullin 3, $N \mathrm{~N}$ terminal end, $C \mathrm{C}$ terminal end

activators have a toxic effect on the human body (Abed et al. 2015; Kerr et al. 2017).

In homeostatic conditions, Nrf2 occurs in cellular cytoplasm and is connected with Keap1 (Kelch-like ECH associating protein 1); in stressful conditions, $\mathrm{Nrf} 2$ dissociates from the inactive Keap1-Nrf2 complex and translocates to the nucleus, where it regulates the expression of genes associated with detoxification (Fig. 2). Multiple mechanisms are involved in dissociation of Nrf2 from Keap1. Some of them might affect Keap1-main regulator, while others can directly interact with Nrf2. Mechanisms that affect the Keap1 protein include: oxidation of cysteine residues in Keap1, an interaction of p62 with Keap1 and phosphorylation of Nrf2 by Protein kinase $\mathrm{C}$ (PKC). Among Keap1-independent mechanisms, $\beta$-TrCP-Cul1-Dependent Pathways and Hrf1Dependent Pathway (Li et al. 2019a) might be distinguished.

The role of Nrf2 in cells is twofold: on the one hand, it protects cells against ROS and decreases DNA damage caused by it, but on the other hand, prolonged expression of this factor is associated with a more aggressive and resistant type of cancers and may be oncogenic (Sporn and Liby 2012). Thus, it seems necessary to evaluate the adverse effect of potential Nrf2 activators in therapy and optimize the dose and exposure to it. Electrophilic and non-electrophilic compounds are two major types of $\mathrm{Nrf} 2$ protein activators. Electrophilic inducers interact with cysteine residues 


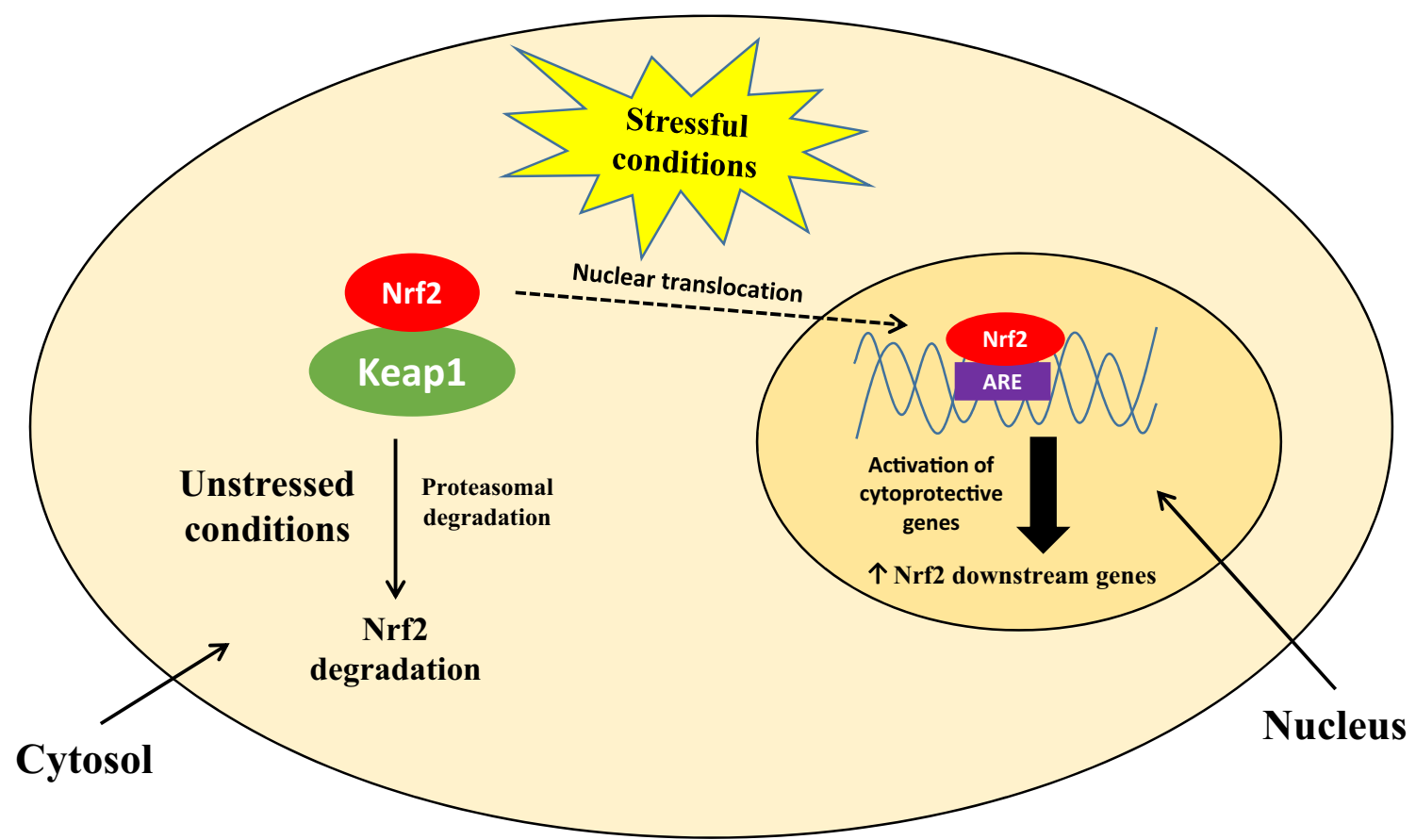

Fig. 2 Schematic diagram showing the behaviour/activity of Nrf2 under stressful and homeostatic conditions. ARE antioxidant responsive element

of Keap1 and thus inactivate E3 ligase. Non-electrophilic inducers disturb the interaction between the Keap1-Nrf2 complex and in consequence, deactivate the Keap1 E3 ligase activity (Suzuki and Yamamoto 2015). Based on the twofold role in physiological and pathophysiological processes, a few pharmacological activators as well as a few clinical trials with the studied Nrf2 inhibitors stating Nrf2 signalling pathway as a potential therapeutic target in the future (Al-Sawaf et al. 2015).

Recently, a lot of toxicological studies on mycotoxins and their effect on human health have suggested that activation of Nrf2 or blockage of this pathway might serve as a potential molecular mechanism of observed toxicity of mycotoxins in human and animal species (Loboda et al. 2017b; Yoon et al. 2019; Huang et al. 2020). Thus, this study was to show if mycotoxins act as activators or inhibitors of the Nrf2 signalling pathway and if Nrf2 serves as the main response element to mycotoxins in human and animal cells. We also tried to find out if natural antioxidants modulating the Nrf2 signalling pathway serve as detoxifying agents in mycotoxins exposure in humans and animals.

\section{Mycotoxins}

Mycotoxins are secondary metabolites of fungi which demonstrate a toxic effect on animal and human health. The direct reason why mycotoxins are produced by fungi has not been explained as yet. They are mainly produced by Aspergillus, Fusarium, Penicillium and Alternaria species. Mycotoxins can be categorized into four major classes, including: aflatoxins (AFs), ochratoxins (OTA), patulin (PAT) and finally, Fusarium toxins, being the most diverse group, including: trichothecenes [deoxynivalenol (DON) and its derivatives, nivalenol (NIV), T-2 and HT-2 toxin], feminises (FMs), zearalenone (ZEA) and its derivatives. Contamination of food with fungi and, consequently, mycotoxins, is contributed by various factors such as: improper harvesting, storage, processing and/or transport of crops. Farm animals present a different degree of sensitivity to mycotoxins; among them, pigs and poultry are reported to be the most sensitive (Yang et al. 2020). The contamination with mycotoxins affects all parts of the food chain, beginning with cultivation, harvesting, processing of food and accumulation in animal tissue. For example, aflatoxin $\mathrm{M}$, a metabolite of aflatoxin B1 may accumulate in eggs (Trucksess et al. 1983; Wolzak et al. 1985) or milk (Nakajima et al. 2004) and be present in the food chain of many products, both processed as well unprocessed. Due to resistance of mycotoxins to heat and chemical treatment during food processing, it is difficult to prevent them from getting contaminated. What is more, mycotoxins occur naturally, thus it is impossible to eliminate them entirely. However, understanding how mycotoxins contamination affects animals and humans is crucial as it enables to identify a proper regulation or possible modulators of toxicity. In response to reports on strong 
adverse effects of mycotoxins on both humans and animals, the Joint FAO/WHO Expert Committee on Food Additives (JECFA) created the maximum recommended daily intake (Table 1). Also the European Food Safety Authority (EFSA) monitors studies on mycotoxins to determine their tolerable daily doses (De Ruyck et al. 2020). Not only is assessment of concentration of mycotoxins in food samples crucial for mycotoxin studies. Understanding of the toxicity mechanism as well as cellular response to mycotoxin exposure allows to evaluate real effects of mycotoxins on human health.

\section{Trichothecenes}

Trichothecenes are a large and structurally diverse group of mycotoxins with average molecular mass between 200 and $500 \mathrm{Da}$. This group includes a number of mycotoxins. However, it seems that types A and B are most toxic for humans and animals. Generally, their cellular effect is based on the interaction with peptidyltransferase enzyme and binding to the 60S ribosomal subunit, which in consequence, inhibits protein synthesis (Marin et al. 2013). Moreover, trichothecenes affect mitochondrial protein synthesis and are able to interact with protein sulfhydryl group (protein-SH groups)- one of the most potent and ubiquitous ligands in biological systems (McCormick et al. 2011).

$\mathrm{T}-2$ toxin is one of the most dangerous secondary metabolite which belongs to type A of trichothecenes. It is produced by various types of Fusarium species. T-2 toxin is metabolized to HT-2 toxin, so it is believed that both the toxins act similarly (Schuhmacher-Wolz et al. 2017). Both mainly occur in cereals (Anfossi et al. 2016). T-2 toxin induces apoptosis and mitochondrial structural disorganization, increases the amount of ROS, and leads to DNA damage (Deyu et al. 2018). Lipophilicity of T-2 is an example of quick absorption by skin, gut and pulmonary mucosa (Zhang et al. 2018b). Neurotoxicity of T-2 was also proven. The effect of T-2 toxin on Nrf2 expression may be different and depend on the time and dose. As Deyu et al. observed in their study, short exposure to T-2 toxin administered in low in doses, resulted in an increased expression of PKA signaling pathway, which in turn led to an increased expression of the Nrf2 transcription factor and PTEN-induced protein kinase 1 (PINK1) (Deyu et al. 2018). This observation is confirmed by the fact that GH3 cells with knock- outed $\mathrm{Nrf} 2$ and exposed to T-2 toxin presented a decreased expression of PINK1, which in consequence confirmed that PKA/Nrf2/ PINK1 signaling pathway is involved in T-2 toxicity in GH3 cells (Deyu et al. 2018). Moreover, in higher doses and during longer exposure, the expression of the Nrf2 transcription factor was downregulated (Chaudhary and Lakshmana Rao 2010; Zhang et al. 2018b). Inhibition of Nrf2 was associated with oxidative stress, mitochondrial dysfunction and activation of p53 in mouse neuroblastoma $2 \mathrm{a}(\mathrm{N} 2 \mathrm{a})$ cells (Zhang et al. 2018b). Nrf2 expression was also significantly decreased in mice exposed to T-2 at a dose of $5.94 \mathrm{mg} / \mathrm{kg}$ as well as phase II detoxifying enzymes NQO1, GCLM and HO-1 (Chaudhary and Lakshmana Rao 2010). This fact suggests that a higher dose of T-2 toxin impairs cellular response to oxidative stress and hereby leading to disruption of the protective pathways. However, it seems necessary to elucidate this concept and more research studies are needed to understand the molecular mechanism of T-2 toxin.

Table 1 Summary information about functions of various mycotoxin and total daily intake doses

\begin{tabular}{|c|c|c|c|}
\hline Mycotoxin & Effect on body & $\begin{array}{l}\text { Total recommended } \\
\text { tolerable daily intake } \\
(\mu \mathrm{g} / \mathrm{kg})\end{array}$ & References \\
\hline Deoxynivalenol & $\begin{array}{l}\text { Genotoxic, impairs the immune response, } \\
\text { reduces fertility and embryotoxicity }\end{array}$ & 1.0 & $\begin{array}{l}\text { Mishra et al. (2014); Yu et al. (2017a); Urbanek } \\
\text { et al. (2018); Habrowska-Górczyńska et al. } \\
\text { (2019) }\end{array}$ \\
\hline Nivalenol & $\begin{array}{l}\text { Impairs the immune response, genotoxic, retards } \\
\text { growth, cause of reproductive disorders, } \\
\text { heameatotoxic and myelotoxic }\end{array}$ & 1.2 & $\begin{array}{l}\text { Bony et al. (2007); Kongkapan et al. (2016); } \\
\text { Schwartz-Zimmermann et al. (2019) }\end{array}$ \\
\hline Zearalenone & $\begin{array}{l}\text { Genotoxic, teratogenic, immunotoxic and cause } \\
\text { of reproductive disorders }\end{array}$ & 0.5 & $\begin{array}{l}\text { Hueza et al. (2014); Lai et al. (2015); Yang et al. } \\
\text { (2018); Zhang et al. (2018a) }\end{array}$ \\
\hline Aflatoxins & $\begin{array}{l}\text { Mutagenic, carcinogenic, hepatotoxic, terato- } \\
\text { genic, immunotoxic, genotoxic }\end{array}$ & 0.00015 & $\begin{array}{l}\text { Peters and Teel (2003); Stettler and Sengstag } \\
\text { (2001); Wangikar et al. (2005); Abnet (2007); } \\
\text { Meissonnier et al. (2008); Abdel-Wahhab et al. } \\
\text { (2010); Zhang et al. (2016) }\end{array}$ \\
\hline Ochratoxin A & $\begin{array}{l}\text { Nephrotoxic, mutagenic, carcinogenic, terato- } \\
\text { genic, immunosuppressive }\end{array}$ & 0.014 & $\begin{array}{l}\text { Kumar et al. (2003); Huff et al. (1975); Gupta } \\
\text { et al. (2005); Marin-Kuan et al. (2006); Solcan } \\
\text { et al. (2013); Malir et al. (2013); Limonciel and } \\
\text { Jennings (2014); Chen et al. (2016) }\end{array}$ \\
\hline $\mathrm{T}-2+\mathrm{HT}-2$ & Immunosuppressive/immunostimulatory ${ }^{\mathrm{a}}$ & 0.06 & Wu et al. (2017) \\
\hline
\end{tabular}

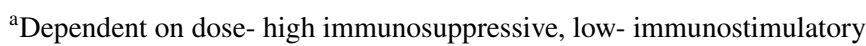


Nevertheless, all studies confirmed that the Nrf2 pathways is attributed to cellular oxidative stress caused by T-2.

Deoxynivalenol (vomitoxin; DON) belongs to type B of the trichothecenes family of mycotoxin produced mainly by Fusarium species (Urbanek et al. 2018) and is considered one of the best known mycotoxins. It is detected in $90 \%$ of tested samples (Sobrova et al. 2010). DON is considered to be one of the most dangerous pollutants occurring naturally in cereal grains, due to its high resistance to processing, grinding and heating (Sugita-Konishi et al. 2006) and is reported to trigger apoptosis, immune response and oxidative stress in cells (Mishra et al. 2014) via disruption of the normal function of mitochondria. DON affects various signaling pathways: RNA-activated protein kinase R (PKR) and hematopoietic cell kinase (Hck), Mitogen-Activated Protein Kinases (MAPKs) (Bae and Pestka 2008). In addition, DON also affects ERK, p38 and JNK and its effect is time- and dose- dependent (Zhou et al. 2003). The main cellular effect of DON includes ribosomal stress in cells-binding of DON to the $28 \mathrm{~S}$ ribosomal RNA peptidyltransferase site, inhibition of protein synthesis-a process called ribotoxic stress response, characteristic for all this group of mycotoxins. Toxic exposure to DON is manifested by vomiting, nausea and diarrhea (Pinton and Oswald 2014).

Mishra et al. observed that the effect of DON on Nrf2 expression was twofold: after 6 and 12 hours of exposure, the expression of Nrf2 got increased, but after 24 hours it decreased (Mishra et al. 2016). Activation of the ERK1/2 signaling pathway might have implied that DON inhibits translocation of $\mathrm{Nrf} 2$ to the nucleus in human $\mathrm{HaCat}$ keratinocytes and thus inhibits transcription of genes involved in the defense mechanism during oxidative stress. The same authors concluded that DON might participate in skin carcinogenesis (Mishra et al. 2016), in which the role of Nrf2 is also controversial (Gęgotek and Skrzydlewska 2015). Intestinal epithelial cells (IECs) are exposed to different factors and constitute the first line in contact with mycotoxins Thus, it is necessary to identify the effect of mycotoxins on intestinal cells to assess a real effect of mycotoxins on human health. In the human colon, adenocarcinoma cell line HT-29 DON disrupted the transport of various components and thus led to disturbance in cellular homeostasis (Maresca et al. 2002). DON-contaminated animal feed decreases nutrient absorption, and in consequence triggers low mass of pigs, mainly in consequence of oxidative stress generated in intestinal cells and activation of $\mathrm{Nrf} 2$ and $\mathrm{NF \kappa B}$ signaling pathways (Zha et al. 2020a). Disruption of intestinal cells caused by DON as well as activation of the Nrf2 signaling pathway and modulation of antioxidants levels were also observed in juvenile grass carp (Huang et al. 2018). A similar effect was observed in human leukemic $\mathrm{T}$ cell lymphoblast Jurkat- 1 cells with activation of NFKB, MAPK and endoplasmic reticulum (ER)-stress induced apoptosis
(Katika et al. 2015) indicating that these signaling pathways are the main response elements in different cell lines to DON exposure.

Del Regno et al. presented that nivalenol (NIV), which is another mycotoxin belonging to the trichothecenes group, may cause oxidative stress in human cells. Moreover, it can enhance the effect of DON (Del Regno et al. 2015; AlassaneKpembi et al. 2017). The cross-contamination with different mycotoxins is commonly observed in food samples. The same research group revealed that in response to oxidative stress induced by NIV or/and DON (mostly when they occur together), the Nrf2 and NF-kB pathways are activated, which suggest that cells defend themselves in this way against damage induced by these mycotoxins (Del Regno et al. 2015). These results are consistent with later reports (Adesso et al. 2017), where the expression of HO-1 is increased during induction, which might be directly associated with activation of Nrf2. This study also showed that NIV and/or DON induces oxidative stress and inflammation in intestinal cells and, in consequence, might participate in common intestinal inflammatory diseases (Del Regno et al. 2015). Another study revealed that single exposure of DON in common carp causes oxidative stress and activates the Nrf2 signaling pathway, explaining liver damage being an effect of exposure to mycotoxins (Kövesi et al. 2020a).

Activation of Nrf2 was also observed in placenta during pregnancy. Yu et al. confirmed that DON induces accumulation of ROS in the placenta and thus leads to structural and functional damage, which negatively affects pregnancy (Yu et al. 2017b, 2018b). Moreover, DON through oxidative stress causes disorders in the embryo's skeleton: cranial/ cervical, rib, clavicle, axial skeleton and limb deformations (Yu et al. 2017b). The Nrf2/HO-1 pathway also appeared to be activated to protect placenta and foetus against oxidative stress (Yu et al. 2017b). Thus, the Nrf2/HO-1 pathway is activated in response to oxidative stress induced by DON and seems to be responsible for DON-caused embryotoxicity. This hypothesis seems to be confirmed by subsequent studies in which DON causes maternal liver damage during pregnancy. However, increased expression of Nrf2/ HO-1 reduces the amount of reactive oxygen species and thus protect hepatocytes against toxicity of this mycotoxin (Yu et al. 2019). Taken together, although ribotoxic stress is believed to be the main cellular response of DON in cells, this literature study allows to conclude that oxidative stress and activation of its main response element, i.e., the Nrf2 signaling pathway, is always associated with the influence of DON on different cells and different individuals.

\section{Zearalenone}

Zearalenone (ZEA, F-2) is a mycotoxin produced mainly by Fusarium species. ZEA is a xenoestrogen due to its 
estrogenic activity caused by chemical similarity to naturally occurring estrogens, mainly $17 \beta$-estradiol that is why, it is called mycoestrogen. ZEA is able to bind to estrogen receptors [mainly estrogen receptor $\alpha(\mathrm{ER} \alpha)$ and/or estrogen receptor $\beta$ (ER $\beta)$ ], disturbs hormonal homeostasis and thus leads to disturbed functioning of the reproductive system, both in humans and animals (Kowalska et al. 2016, 2018). In consequence, it may lead to the development and progression of hormone-dependent cancer such as breast, cervical, endometrial, ovarian and prostate cancer (Ahamed et al. 2001; Mungenast and Thalhammer 2014; Bronowicka-Kłys et al. 2016). Exposure to mycoestrogens is associated with many different ways of providing: food, water, pesticides, air, cosmetics, plants and medicines. Contamination with ZEA occurs mostly in corn, wheat, rice and barley. Living organisms are able to defend itself against xenobiotics in many different ways, one of which is the phase I and II detoxication enzymes produced in the liver. However, based on research reports the phase I metabolites of ZEA $\alpha$-zearalenol $(\alpha-Z O L)$ and $\beta$-zearalenol ( $\beta$-ZOL) are also estrogenic and even more estrogenic that ZEA itself (Catteuw et al. 2019). On molecular level ZEA both stimulates the proliferation of cells in low doses as well as induces apoptosis, autophagy and oxidative stress in higher doses (Zheng et al. 2018). Although there is a lot of studies concerning the effect of ZEA on human and animal cell lines, only a few of them evaluated the activation of Nrf2 by ZEA. PI3K-Akt, Nrf2 and ER-stress were associated with the effect of ZEA on murine Leydig cells and associated with apoptosis and oxidative stress. Moreover, the same study confirmed that curcumin might protects Leydig cells from ZEA-induced oxidative stress via reduction of total expression and increase in nucleus expression of Nrf2 (Chen et al. 2020). Similar study was conducted on mice Sertoli cells, where ZEA induced apoptosis via Nrf2/ARE signalling pathway associated with oxidative stress induction in cells (Long et al. 2017). Yoon et al. showed that ZEA led to increased expression of Nrf2 in human liver cancer cells lines (HepG2); moreover, this relationship was only observed in smaller concentration of this mycotoxin for which usually the estrogenic pro-proliferative effect is observed. Oxidative damage caused by ZEA was also observed in mice liver, where ZEA significantly reduced expression of Nrf2 (Long et al. 2016). An increased expression of Nrf2 was associated with apoptosis, ER-stress and autophagy in human liver cells (Yoon et al. 2019). Similar relationship was observed in another study: Liu et al. showed that Nrf2 expression was increased in intestinal tissue of pregnant rats after induction with ZEA and postulated that modulation of Nrf2 signalling pathway is a main response element in gut cells. This effect was simultaneous with formation of ROS and inflammatory status in cells (Liu et al. 2014). Based on Cheng and al. study along with the increasing concentration of ZEA the Keap1-Nrf2 pathway increases, which causes an upregulation in the expression of genes activated by the Nrf2 transcription factor. The similar results were observed in the ileum and mesenteric lymph nodes of post-weaning gilts (Cheng et al. 2019, 2020). Nrf2 activation in response to ZEA-induced oxidative stress was also observed in juvenile grass carp intestine; however, no changes in Keap1 levels were observed (Wang et al. 2019). The molecular effect of ZEA, mostly considered with its estrogenic properties in cells, is associated with induction od oxidative stress-induced apoptosis or autophagy and thus activation of $\mathrm{Nrf} 2$ is reported, especially in consideration of protective compounds which aim to reduce ZEA-induced oxidative stress. However, many research studies reporting ZEA-induced apoptosis did not consider Nrf2 signalling pathway as a molecular effect of ZEA, although oxidative stress induced by environmental factors is known to trigger different types of death in cells, e.g., necrosis, apoptosis and the role of Nrf2 seems to be crucial in these processes (Nam and Keum 2019).

\section{Ochratoxin A}

Aspergillus and Penicillium fungi are mainly producing ochratoxins (OTs). These mycotoxins are found in various food products: cereals, dried fruit, meat, red wine, beer, nuts and coffee. The most dangerous member of this family is Ochratoxin A (OTA), classified as type 2B carcinogen, which has been found recently also in herbs used in traditional medicine (Veprikova et al. 2015; Chen et al. 2015; Su et al. 2018; Toman et al. 2018). OTA leads to many disorders both in humans and animals. After absorption, OTA is able to bind to albumin and in consequence, its half-life in the body is prolonged (Kôszegi and Poór 2016). Products of OTA metabolism are formed mainly via hydrolysis, hydroxylation, lactone opening and conjugation (Wu et al. 2011; Tao et al. 2018). Similarly to other mycotoxins, OTA is reported to enhance production of ROS and thus led to disturbance in cell cycle (Liu et al. 2012) and DNA, lipid and protein damage (Marin-Kuan et al. 2011). Its carcinogenicity is mainly associated with nephro- and hepato-toxicity (Marin-Kuan et al. 2011). It is proved that OTA affects expression of transcription factors involved in oxidative stress response. OTA reduces the expression of detoxifying enzymes via modulation of Nrf2 activity (Marin-Kuan et al. 2011). In the study of Boesh-Saadatamandi et al. OTA decreased expression of Nrf2 and HO-1 (and its downstream genes) in cells derived from pigs kidney and the authors postulated that downregulation of Nrf2 might be partially responsible for nephrotoxicity of OTA (Boesch-Saadatmandi et al. 2009). A similar effect was observed in porcine renal proximal tubular cells (Stachurska et al. 2013). In turn, Shanel et al. showed that OTA in human embryonic kidney cells (HEK293) induced expression of NF-KB (Raghubeer et al. 2017). Due to the fact 
that this factor is Nrf2 regulator, it seems that the expression of Nrf2 in these cells might be also affected. Interestingly, not only Nrf2 but its downstream target HO-1 might play a protective role in OTA toxicity: it was observed that OTA significantly affects murine kidneys. Furthermore, HO-1 knockout mice presented acceleration of OTA-induced fibrogenic, inflammatory and apoptotic effect (Loboda et al. 2017a). Similar effect was observed in mice lacking Nrf2 and interestingly, male mice were more sensitive to this effect than females, suggesting that the effect of its toxicity depends on gender (Loboda et al. 2017b). The decrease in Nrf2 activation induced by OTA was also observed in NRK$52 \mathrm{E}$ rat kidney cells were the influence of another oxidative stress regulator was suggested: hypoxia inducible factor $1 \alpha$ (HIF-1 $\alpha$ ) which activation was associated with angiogenesis (Liu et al. 2020). Induction of apoptosis and oxidative stress by OTA in chicken kidneys and liver was associated with modulation of Nrf2/Keap1 as well as PI3K/Akt signalling pathways as confirmed by Li et al. (2020a). The decreasing expression of Nrf2 and HO-1 was also observed after treatment of porcine renal proximal tubular cells with OTA (Stachurska et al. 2013). Shin et al. showed that OTA-induced oxidative stress in human hepatocytes is associated with aryl hydrocarbon receptor (AhR) as well as Nrf2, additionally the increase in the expression as well as nuclear localization of Nrf2 was observed (Shin et al. 2019). This fact suggests that phase II reactions are highly dependent on phase I detoxifying reactions in cell in response to OTA. OTA-induced liver injury was also observed in ducks, Zhai et al. indicated that observed effect might be modulated by antioxidants modulating intestinal microbiota such as tryptophan and glyceropholipid metabolism, significantly affected by OTA in ducks (Zhai et al. 2020). OTA induces oxidative stress and in consequence injury in murine heart muscle via Nrf2 signalling pathway: a decrease in heart weight, increased serum concentration of cardiac enzymes and antioxidant levels were observed (Cui et al. 2020). OTA, possibly due to its known carcinogenicity, in most of the studies decreases Nrf2 and its downstream targets in cells, whereas natural antioxidants are able to restore the OTA-induced decrease of Nrf2.

\section{Aflatoxin B1}

More than 20 aflatoxins (AFs) are produced by Asperegillus species, mainly by Aspergillus flavus and Aspergillus parasiticus. AFs are slightly soluble in water and soluble in polar solvents. AFs presents acute toxicity at high doses and chronic toxicity at low doses (Ülger et al. 2020). AFs are absorbed in duodenum and transported to the liver- the most exposed organ to AFs toxicity, due to the first line of metabolism of these mycotoxins. However, AFs also affect others tissues such as kidney, pancreas or bladder (Benkerroum 2020). Six major AFs are distinguished: B1, B2, G1,
G2, M1 and M2 from which Aflatoxin B1 (AFB1) is the most dangerous form, classified ascarcinogen 1 according to International Agency for Research on Cancer (IARC) (Ülger et al. 2020). AFB1 induces oxidative stress, leads to DNA damage and disturbance in mitochondrial permeability which was proved in tissues derived from different organisms (Theumer et al. 2010; Abdel-Aziem et al. 2011; Shi et al. 2015). As a carcinogen AFB1 induces DNA strand breaks, chromosomal abnormalities and mutation in p53 gene (Corcuera et al. 2015). As the result of AFB1 metabolism, Aflatoxin M1 may be formed, which is less carcinogenic than AFB1 (Wen et al. 2016). However, AFB1 may be metabolized by CYP450 to AFB1-exo-8,9-epoxide (AFBO)- a reactive form which binds to nucleic acids, proteins and thus lead to apoptosis, DNA-damage, disruption in signalling pathways and protein synthesis (Benkerroum 2020). One of the signalling pathways influenced by AFB1 seems to be Nrf2 pathway. Activation of Nrf2 was present in the most exposed organ to AFB1: liver. It was presented that AFB1 leads to decreased expression of Nrf2 and its downstream gene HO-1, simultaneously with oxidative stress and pro-inflammatory cytokines response in broiler chickens $(\mathrm{Li}$ et al. 2019b). Induction of Nrf2 signalling pathway was also observed in common carp (Kövesi et al. 2020b). The experiment conducted on human hepatocytes L02 cells revealed that caveolin-1 (CAV-1) interacts with Nrf2 in response to oxidative stress caused by AFB 1 to trigger apoptosis in cells (Xu et al. 2020). A decrease in Nrf2 and HO-1 expression was also noticed in Wistar rats exposed to AFB1 and interestingly that effect was partially restored by administration of antidiabetic drug Sitagliptin (Ji et al. 2020). AFB1 affects lipid mitochondrial metabolism and oxidative stress response element Nrf2 after acute exposure in rats (Rotimi et al. 2019). Muhammad et al. suggested that AFB1 does not cause autophagy in broiler chicken livers, but induces inflammation and reduces expression of $\mathrm{Nrf} 2$ and $\mathrm{HO}-1$, indicating that the switch between autophagy and inflammation might play a crucial role in AFB1 induced hepatotoxicity (Muhammad et al. 2018). Human hepatic HepG2 cells exposed to AFB1 presented an increased oxidative stress and hepatotoxicity with DNA damage and cytotoxicity with downregulation of Nrf2/HO-1 signalling pathway (Vipin et al. 2017). On the other hand, in primary broiler hepatocytes AFB1 caused upregulation of Nrf2 although the expression of its downstream genes decreased (Liu and Wang 2016). In broiler cardiomyocytes Wang et al. observed that AFB1 also upregulates expression of Nrf2 (Wang et al. 2017). It should be emphasized, that $N r f 2$ knockout rats are more susceptible than wild type to toxic effect of AFB 1 via decreased expression of its downstream genes (Taguchi et al. 2016). Based on the fact that AFB1 is a carcinogen, its effect on other tissues was also investigated. Zhou et al. observed that similarly to liver tissue, AFB1 induces cytotoxicity, 
oxidative stress and apoptosis in cow mammary epithelial cells associated with increase in the expression of Nrf2 signalling pathway components: Nrf2, Keap1, NQO1 and HO-1 after 3 hours of exposure (Zhou et al. 2019). The decreased expression of Nrf2 signalling pathway components was also observed in murine renal cells exposed to AFB1 (Yu et al. 2018a). Based on these studies Nrf2 seems to participate in carcinogenic effect of AFB1 and potentially the activators of Nrf2 signalling pathways both natural as well as chemical might serve as AFB1 detoxifying enzymes.

\section{Natural antioxidants}

Due to fact that Nrf2 signalling pathway seems to participate in the toxic effect of mycotoxins on human and animal cells, searching of new antioxidative agents that in most cases activates Nrf2 expression, constitutes the aim of many research studies. In most cases, natural antioxidants are taken into consideration. Natural antioxidants are a group of chemical compounds extracted from plants which are commonly used in pharmacy as a supplements of diet or drugs used to prevent diseases. Many of the natural antioxidants are known to decrease oxidative stress induced by mycotoxins by restoring the expression of Nrf2 and its downstream targets (Table 2).
The extract of Scutellaria baicalensis, known as baicalin, is a flavonoid which easily chelates with $\mathrm{Zn}$ and $\mathrm{Cu}$ to form a metal chelate complexes which possesses a higher antioxidant capabilities than flavonoid itself. Dietary supplemented baicalin zinc reduced DON-induced expression of p-Nrf2 and HO-1 in the piglets intestine (Zha et al. 2020a). Similar effect was observed for the complex of baicalin copper in another study (Zha et al. 2020b). Grape seed proanthocyanidin extract increased the expression of $\mathrm{Nrf} 2$ and its downstream genes decreased in the response to oxidative stress triggered by ZEA in murine liver and Sertoli cells (Long et al. 2016, 2017) as well as AFB1 induced oxidative stress and inflammation in broilers (Rajput et al. 2019). Curcumin seems to serve as Nrf2 activator in response to different mycotoxins. The increase in the expression of $\mathrm{Nrf} 2$ after curcumin exposure was present in ZEA- treated Leydig cells (Chen et al. 2020), AFB1- treated liver cells (Muhammad et al. 2018; Li et al. 2019b) and OTA- treated liver cells in ducks (Zhai et al. 2020). The toxic effect of AFB1 was also abolished by resveratrol in bovine mammary epithelial cell via modulation of Nrf2 (Zhou et al. 2019). Another natural compounds reported to increase the expression of Nrf2 in AFB1 treated cells are: lycopene (Yu et al. 2018a), ginger extract (Vipin et al. 2017) and coffee (Cavin et al. 2008). The phenolics rich extract of ginger in in vivo and

Table 2 Summary information about natural antioxidants affecting the expression of Nrf2 and its downstream genes after exposure to various mycotoxins

\begin{tabular}{|c|c|c|c|c|}
\hline Mycotoxin & Natural ingredients & $\begin{array}{l}\text { Influence } \\
\text { on Nrf2 }\end{array}$ & Influence on $\mathrm{Nrf} 2$ downstream genes & References \\
\hline \multirow[t]{3}{*}{ DON } & Resveratrol & $\uparrow$ & $\uparrow$ GCLM, GCLC & Yang et al. (2019) \\
\hline & Baicalin zinc & $\downarrow$ & $\downarrow \mathrm{HO}-1$ & Zha et al. (2020a) \\
\hline & Baicalin copper & $\downarrow$ & $\downarrow \mathrm{HO}-1$ & Zha et al. (2020b) \\
\hline \multirow[t]{2}{*}{ ZEA } & Grape-seed proanthocyanidin extract & $\uparrow$ & $\uparrow \mathrm{HO}-1, \mathrm{NQO} 1, \gamma$-GCS & Long et al. (2016) \\
\hline & Curcumin & $\uparrow$ & 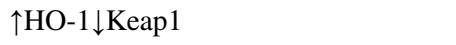 & Chen et al. (2020) \\
\hline \multirow[t]{6}{*}{ AFB1 } & Curcumin & $\uparrow$ & $\uparrow \mathrm{HO}-1$ & $\begin{array}{l}\text { Zhang et al. (2016); Wang et al. (2018); } \\
\text { Muhammad et al. (2018); Li et al. } \\
\text { (2019b) }\end{array}$ \\
\hline & Phenolics of ginger ${ }^{\mathrm{a}}$ & $\uparrow$ & $\uparrow \mathrm{HO}-1$ & Vipin et al. (2017) \\
\hline & Resveratrol & $\uparrow$ & $\uparrow \mathrm{HO}-1, \mathrm{NQO} 1$ & Zhou et al. (2019) \\
\hline & Grape-seed proanthocyanidin extract & $\uparrow$ & $\uparrow \mathrm{HO}-1$, GPx1, NQO1, GCLC & Rajput et al. (2019) \\
\hline & Coffee & $\uparrow$ & $\uparrow \mathrm{HO}-1, \mathrm{GCLC}, \mathrm{NQO} 1$ & Cavin et al. (2008) \\
\hline & Lycopene & $\uparrow$ & $\uparrow$ NQO1, GCLM, GCLC & Yu et al. (2018a) \\
\hline \multirow[t]{5}{*}{ OTA } & Quercetin $^{\mathrm{b}}$ & $\uparrow$ & - & $\begin{array}{l}\text { Ramyaa and Padma (2013); Ramyaa et al. } \\
\text { (2014) }\end{array}$ \\
\hline & Luteolin & $\uparrow$ & $\uparrow \mathrm{HO}-1, \gamma$-GCS and Gpx-1 & Liu et al. (2020) \\
\hline & Astaxanthin & $\uparrow$ & $\downarrow$ Keap-1, $\uparrow$ HO- 1 & Cui et al. (2020) \\
\hline & Yeast selenium (Se-Y) & $\uparrow$ & $\uparrow \mathrm{HO}-1, \mathrm{GSH}-\mathrm{px}, \mathrm{GLRX} 2$ & Li et al. $(2020 a, c)$ \\
\hline & Curcumin & $\uparrow$ & $\uparrow \mathrm{HMOX} 1$ & Zhai et al. (2020) \\
\hline
\end{tabular}

$\downarrow$ downregulated, $\uparrow$ upregulated

${ }^{\mathrm{a}}$ In human cells

${ }^{\mathrm{b}}$ In human and animal cells 
in vitro study showed to limit hepatotoxic effect of AFB1. Moreover, it was proved that administration of extract from ginger led to increased expression of Nrf2/HO-1 pathway (Vipin et al. 2017). Coffee has an impact in the prevention against ROS produced in response to AFB1 via induction of Nrf2/ARE pathway (Cavin et al. 2008). Lycopene protected AFB1- induced renal injury in mice (Yu et al. 2018a). Similarly to AFB1, OTA-induced decrease in Nrf2 expression associated with oxidative stress might be also attenuated by natural antioxidants. Flavonoid luteolin regulates Nrf2 and HIF- $1 \alpha$ signalling pathways to alleviate OTA-induced oxidative stress (Liu et al. 2020). Carotenoid astaxanthin similarly to luteolin protects against OTA-induced kidney injury ( $\mathrm{Li}$ et al. 2020b), similarly to yeast selenium used as diet supplement ( $\mathrm{Li}$ et al. 2020c). Also quercetin, a natural flavanol, stimulates translocation of Nrf2 to the nucleus and increases its expression after cell exposure to OTA and thus alleviate the toxicity of this mycotoxin (Ramyaa and Padma 2013; Ramyaa et al. 2014).

\section{Conclusions}

It is generally known that mycotoxins affect human and animal cells by disruption of homeostasis and consequently generation of oxidative stress. It is also known that we are not able to eliminate mycotoxins contamination in food, but understanding its molecular effect on human and animal health might help to search for potential detoxifying agents. Studies from last years showed that Nrf2 transcription factor might play a crucial role in the cellular defence mechanisms. This review confirmed that the most common and well known mycotoxins affect expression of Nrf2 factor and thus lead to decreased expression of its downstream genes which are directly involved in the detoxification of the organism. Interestingly, this literature survey also suggested that the effect of mycotoxins on Nrf2 expression is more complex and involved different singling pathways: Nrf2/ ARE, HIF-1 $\alpha$, PI3K/Akt, Ahr etc. Nevertheless, in most studies Nrf2 expression and its localization is affected and thus seems to appear as a good target for potential drugs and/or antioxidants. In most of the cases mycotoxins caused decreased expression of $\mathrm{Nrf}$, however, it should be emphasized that Nrf2 might play a dual role in cells and thus more research studies should be carried out in the future to both evaluate Nrf2 role in mycotoxins detoxication as well as its potential activators serving as mycotoxins detoxifying agents.

Author contributions AWP-C and KK conceptualized the study, MJK conducted the literature survey, MJK and KK wrote the manuscript. All authors reviewed and revised the manuscript.
Funding This study was supported by Medical University of Lodz Grant no. 503/0-078-03/503-01-001-19-00.

\section{Compliance with ethical standards}

Conflicts of interest The authors declare no conflict of interest.

Open Access This article is licensed under a Creative Commons Attribution 4.0 International License, which permits use, sharing, adaptation, distribution and reproduction in any medium or format, as long as you give appropriate credit to the original author(s) and the source, provide a link to the Creative Commons licence, and indicate if changes were made. The images or other third party material in this article are included in the article's Creative Commons licence, unless indicated otherwise in a credit line to the material. If material is not included in the article's Creative Commons licence and your intended use is not permitted by statutory regulation or exceeds the permitted use, you will need to obtain permission directly from the copyright holder. To view a copy of this licence, visit http://creativecommons.org/licenses/by/4.0/.

\section{References}

Abdel-Aziem SH, Hassan AM, Abdel-Wahhab MA (2011) Dietary supplementation with whey protein and ginseng extract counteracts oxidative stress and DNA damage in rats fed an aflatoxin-contaminated diet. Mutat Res 723:65-71. https://doi.org/10.1016/j. mrgentox.2011.04.007

Abdel-Wahhab MA, Hassan NS, El-Kady AA et al (2010) Red ginseng extract protects against aflatoxin B1 and fumonisins-induced hepatic pre-cancerous lesions in rats. Food Chem Toxicol 48:733-742. https://doi.org/10.1016/j.fct.2009.12.006

Abed DA, Goldstein M, Albanyan H et al (2015) Discovery of direct inhibitors of Keap1-Nrf2 protein-protein interaction as potential therapeutic and preventive agents. Acta Pharm Sin B 5:285-299

Abnet CC (2007) Carcinogenic food contaminants. Cancer Invest 25:189-196

Adesso S, Autore G, Quaroni A et al (2017) The food contaminants nivalenol and deoxynivalenol induce inflammation in intestinal epithelial cells by regulating reactive oxygen species release. Nutrients. https://doi.org/10.3390/nu9121343

Ahamed S, Foster JS, Bukovsky A, Wimalasena J (2001) Signal transduction through the Ras/Erk pathway is essential for the mycoestrogen zearalenone-induced cell-cycle progression in MCF-7 cells. Mol Carcinog 30:88-98. https://doi.org/10.1002/10982744(200102)30:2\%3c88::aid-mc1017\%3e3.0.co;2-e

Alassane-Kpembi I, Puel O, Pinton P et al (2017) Co-exposure to low doses of the food contaminants deoxynivalenol and nivalenol has a synergistic inflammatory effect on intestinal explants. Arch Toxicol 91:2677-2687. https://doi.org/10.1007/s0020 4-016-1902-9

Al-Sawaf O, Clarner T, Fragoulis A et al (2015) Nrf2 in health and disease: current and future clinical implications. Clin Sci 129:989-999

Anfossi L, Giovannoli C, Baggiani C (2016) Mycotoxin detection. Curr Opin Biotechnol 37:120-126. https://doi.org/10.1016/J.COPBI O.2015.11.005

Aoki Y, Sato H, Nishimura N et al (2001) Accelerated DNA adduct formation in the lung of the Nrf2 knockout mouse exposed to diesel exhaust. Toxicol Appl Pharmacol 173:154-160. https:// doi.org/10.1006/taap.2001.9176 
Bae HK, Pestka JJ (2008) Deoxynivalenol induces p38 interaction with the ribosome in monocytes and macrophages. Toxicol Sci 105:59-66. https://doi.org/10.1093/toxsci/kfn102

Banerjee S, Ghosh S, Mandal A et al (2020) ROS-associated immune response and metabolism: a mechanistic approach with implication of various diseases. Arch Toxicol 1:3. https://doi. org/10.1007/s00204-020-02801-7

Benkerroum N (2020) Chronic and acute toxicities of aflatoxins: mechanisms of action. Int J Environ Res Public Health 17:423

Boesch-Saadatmandi C, Wagner AE, Graeser AC et al (2009) Ochratoxin A impairs Nrf2-dependent gene expression in porcine kidney tubulus cells. J Anim Physiol Anim Nutr (Berl) 93:547-554. https://doi.org/10.1111/j.1439-0396.2008.00838.x

Bony S, Olivier-Loiseau L, Carcelen M, Devaux A (2007) Genotoxic potential associated with low levels of the Fusarium mycotoxins nivalenol and fusarenon $\mathrm{X}$ in a human intestinal cell line. Toxicol Vitr 21:457-465. https://doi.org/10.1016/j.tiv.2006.10.014

Bronowicka-Kłys DE, Lianeri M, Jagodziński PP (2016) The role and impact of estrogens and xenoestrogen on the development of cervical cancer. Biomed Pharmacother 84:1945-1953

Catteuw A, Broekaert N, De Baere S et al (2019) Insights into in vivo absolute oral bioavailability, biotransformation, and toxicokinetics of zearalenone, $\alpha$-zearalenol, $\beta$-zearalenol, zearalenone14-glucoside, and zearalenone-14-sulfate in pigs. J Agric Food Chem 67:3448-3458. https://doi.org/10.1021/acs.jafc.8b05838

Cavin C, Marin-Kuan M, Langouët S et al (2008) Induction of Nrf2mediated cellular defenses and alteration of phase I activities as mechanisms of chemoprotective effects of coffee in the liver. Food Chem Toxicol 46:1239-1248. https://doi.org/10.1016/j. fct.2007.09.099

Chaudhary M, Lakshmana Rao PV (2010) Brain oxidative stress after dermal and subcutaneous exposure of T-2 toxin in mice. Food Chem Toxicol 48:3436-3442. https://doi.org/10.1016/J. FCT.2010.09.018

Chen AJ, Jiao X, Hu Y et al (2015) Mycobiota and mycotoxins in traditional medicinal seeds from China. Toxins (Basel) 7:3858-3875. https://doi.org/10.3390/toxins7103858

Chen B, Li D, Li M et al (2016) Induction of mitochondria-mediated apoptosis and PI3K/Akt/mTOR-mediated autophagy by aflatoxin B2 in hepatocytes of broilers. Oncotarget 7:84989-84998. https ://doi.org/10.18632/oncotarget.13356

Chen S, Yang S, Wang M et al (2020) Curcumin inhibits zearalenoneinduced apoptosis and oxidative stress in Leydig cells via modulation of the PTEN/Nrf2/Bip signaling pathway. Food Chem Toxicol 141:111385. https://doi.org/10.1016/j.fct.2020.111385

Cheng D, Wu R, Guo Y, Kong ANT (2016) Regulation of Keap1-Nrf2 signaling: the role of epigenetics. Curr Opin Toxicol 1:134-138

Cheng Q, Jiang S, Huang L et al (2019) Zearalenone induced oxidative stress in the jejunum in postweaning gilts through modulation of the Keap1-Nrf2 signaling pathway and relevant genes. J Anim Sci 97:1722-1733. https://doi.org/10.1093/jas/skz051

Cheng Q, Jiang S, Huang L et al (2020) Effects of zearalenone-induced oxidative stress and Keap1-Nrf2 signaling pathway-related gene expression in the ileum and mesenteric lymph nodes of postweaning gilts. Toxicology 429:152337. https://doi.org/10.1016/j. tox.2019.152337

Corcuera LA, Vettorazzi A, Arbillaga L et al (2015) Genotoxicity of aflatoxin B1 and ochratoxin A after simultaneous application of the in vivo micronucleus and comet assay. Food Chem Toxicol 76:116-124. https://doi.org/10.1016/j.fct.2014.12.003

Cui G, Li L, Xu W et al (2020) Astaxanthin protects ochratoxin A-induced oxidative stress and apoptosis in the heart via the Nrf2 pathway. Oxid Med Cell Longev. https://doi. org/10.1155/2020/7639109

De Ruyck K, Huybrechts I, Yang S et al (2020) Mycotoxin exposure assessments in a multi-center European validation study by 24-hour dietary recall and biological fluid sampling. Environ Int. https://doi.org/10.1016/j.envint.2020.105539

Del Regno M, Adesso S, Popolo A et al (2015) Nivalenol induces oxidative stress and increases deoxynivalenol pro-oxidant effect in intestinal epithelial cells. Toxicol Appl Pharmacol 285:118-127. https://doi.org/10.1016/j.taap.2015.04.002

Deyu H, Luqing C, Xianglian L et al (2018) Protective mechanisms involving enhanced mitochondrial functions and mitophagy against T-2 toxin-induced toxicities in GH3 cells. Toxicol Lett 295:41-53. https://doi.org/10.1016/j.toxlet.2018.05.041

Enomoto A, Itoh K, Nagayoshi E et al (2001) High sensitivity of Nrf2 knockout mice to acetaminophen hepatotoxicity associated with decreased expression of ARE-regulated drug metabolizing enzymes and antioxidant genes. Toxicol Sci 59:169-177. https ://doi.org/10.1093/toxsci/59.1.169

Gęgotek A, Skrzydlewska E (2015) The role of transcription factor Nrf2 in skin cells metabolism. Arch Dermatol Res 307:385-396

Guo Y, Yu S, Zhang C, Kong ANT (2015) Epigenetic regulation of Keap1-Nrf2 signaling. Free Radic Biol Med 88:337-349

Gupta S, Jindal N, Khokhar RS et al (2005) Effect of ochratoxin A on broiler chicks challenged with Salmonella gallinarum. Br Poult Sci 46:443-450. https://doi.org/10.1080/00071660500190850

Habrowska-Górczyńska DE, Kowalska K, Urbanek KA et al (2019) Deoxynivalenol modulates the viability, ROS production and apoptosis in prostate cancer cells. Toxins (Basel) 11:265. https ://doi.org/10.3390/toxins 11050265

Hayes JD, Dinkova-Kostova AT (2014) The Nrf2 regulatory network provides an interface between redox and intermediary metabolism. Trends Biochem Sci 39:199-218. https://doi. org/10.1016/J.TIBS.2014.02.002

Hirotsu Y, Katsuoka F, Funayama R et al (2012) Nrf2-MafG heterodimers contribute globally to antioxidant and metabolic networks. Nucleic Acids Res 40:10228-10239. https://doi. org/10.1093/nar/gks827

Huang C, Wu P, Jiang WD et al (2018) Deoxynivalenol decreased the growth performance and impaired intestinal physical barrier in juvenile grass carp (Ctenopharyngodon idella). Fish Shellfish Immunol 80:376-391. https://doi.org/10.1016/j. fsi.2018.06.013

Huang C, Feng L, Liu X-A et al (2020) The toxic effects and potential mechanisms of deoxynivalenol on the structural integrity of fish gill: oxidative damage, apoptosis and tight junctions disruption. Toxicon 174:32-42. https://doi.org/10.1016/J.TOXIC ON.2019.12.151

Hueza IM, Raspantini PCF, Raspantini LER et al (2014) Zearalenone, an estrogenic mycotoxin, is an immunotoxic compound. Toxins (Basel) 6:1080-1095. https://doi.org/10.3390/toxins6031080

Huff WE, Wyatt RD, Hamilton PB (1975) Nephrotoxicity of dietary ochratoxin A in broiler chickens. Appl Microbiol 30:48-51

Ji Y, Nyamagoud SB, SreeHarsha N et al (2020) Sitagliptin protects liver against aflatoxin B1-induced hepatotoxicity through upregulating Nrf2/ARE/HO-1 pathway. BioFactors 46:76-82. https:// doi.org/10.1002/biof. 1573

Katika MR, Hendriksen PJM, van Loveren H, Peijnenburg AACM (2015) Characterization of the modes of action of deoxynivalenol (DON) in the human Jurkat T-cell line. J Immunotoxicol 12:206-216. https://doi.org/10.3109/1547691X.2014.925995

Kerr F, Sofola-Adesakin O, Ivanov DK et al (2017) Direct Keap1Nrf2 disruption as a potential therapeutic target for Alzheimer's disease. PLoS Genet 13:e1006593. https://doi.org/10.1371/journ al.pgen.1006593

Kim J-H, Yu S, Chen JD, Kong AN (2013) The nuclear cofactor RAC3/AIB1/SRC-3 enhances Nrf2 signaling by interacting with transactivation domains. Oncogene 32:514-527. https:// doi.org/10.1038/onc.2012.59 
Kongkapan J, Giorgi M, Poapolathep S et al (2016) Toxicokinetics and tissue distribution of nivalenol in broiler chickens. Toxicon 111:31-36. https://doi.org/10.1016/j.toxicon.2015.12.013

Kőszegi T, Poór M (2016) Ochratoxin a: molecular interactions, mechanisms of toxicity and prevention at the molecular level. Toxins (Basel) 8:111

Kövesi B, Kulcsár S, Zándoki E et al (2020a) Short-term effects of deoxynivalenol, T-2 toxin, fumonisin B1 or ochratoxin on lipid peroxidation and glutathione redox system and its regulatory genes in common carp (Cyprinus carpio L.) liver. Fish Physiol Biochem. https://doi.org/10.1007/s10695-020-00845-1

Kövesi B, Pelyhe C, Zándoki E et al (2020b) Combined effects of aflatoxin $\mathrm{B} 1$ and deoxynivalenol on the expression of glutathione redox system regulatory genes in common carp. J Anim Physiol Anim Nutr (Berl). https://doi.org/10.1111/jpn.13343

Kowalska K, Habrowska-Górczyńska DE, Piastowska-Ciesielska AW (2016) Zearalenone as an endocrine disruptor in humans. Environ Toxicol Pharmacol 48:141-149

Kowalska K, Habrowska-Górczyńska DE, Urbanek KA et al (2018) Estrogen receptor $\alpha$ is crucial in zearalenone-induced invasion and migration of prostate cancer cells. Toxins (Basel). https:// doi.org/10.3390/toxins 10030098

Kumar A, Jindal N, Shukla CL et al (2003) Effect of ochratoxin A on Escherichia coli-challenged broiler chicks. Avian Dis 47:415424. https://doi.org/10.1637/0005-2086(2003)047[0415:EOOAO E]2.0.CO;2

Kwak M-K, Itoh K, Yamamoto M, Kensler TW (2002) Enhanced expression of the transcription factor Nrf2 by cancer chemopreventive agents: role of antioxidant response element-like sequences in the Nrf2 promoter. Mol Cell Biol 22:2883-2892. https://doi.org/10.1128/MCB.22.9.2883-2892.2002

Lai F-N, Ma J-Y, Liu J-C et al (2015) The influence of $N$-acetyl- $l$ cysteine on damage of porcine oocyte exposed to zearalenone in vitro. Toxicol Appl Pharmacol 289:341-348. https://doi. org/10.1016/j.taap.2015.09.010

Li R, Jia Z, Zhu H (2019a) Regulation of Nrf2 signaling. React Oxyg species (Apex) 8:312-322

Li S, Muhammad I, Yu H et al (2019b) Detection of aflatoxin adducts as potential markers and the role of curcumin in alleviating AFB1-induced liver damage in chickens. Ecotoxicol Environ Saf 176:137-145. https://doi.org/10.1016/j.ecoenv.2019.03.089

Li K, Cao Z, Guo Y et al (2020a) Selenium yeast alleviates ochratoxin A-induced apoptosis and oxidative stress via modulation of the PI3K/AKT and Nrf2/Keap1 signaling pathways in the kidneys of chickens. Oxid Med Cell Longev. https://doi. org/10.1155/2020/4048706

Li L, Chen Y, Jiao D et al (2020b) Protective effect of astaxanthin on ochratoxin A-induced kidney injury to mice by regulating oxidative stress-related Nrf2/Keap1 pathway. Molecules. https://doi. org/10.3390/molecules 25061386

Li P, Li K, Zou C et al (2020c) Selenium yeast alleviates ochratoxin A-induced hepatotoxicity via modulation of the PI3K/AKT and Nrf2/Keap1 signaling pathways in chickens. Toxins (Basel) 12:143. https://doi.org/10.3390/toxins12030143

Limonciel A, Jennings P (2014) A review of the evidence that ochratoxin A is an Nrf2 inhibitor: implications for nephrotoxicity and renal carcinogenicity. Toxins (Basel) 6:371-379. https://doi. org/10.3390/toxins6010371

Liu Y, Wang W (2016) Aflatoxin B1 impairs mitochondrial functions, activates ROS generation, induces apoptosis and involves $\mathrm{Nrf} 2$ signal pathway in primary broiler hepatocytes. Anim Sci J 87:1490-1500. https://doi.org/10.1111/asj.12550

Liu J, Wang Y, Cui J et al (2012) Ochratoxin A induces oxidative DNA damage and G1 phase arrest in human peripheral blood mononuclear cells in vitro. Toxicol Lett 211:164-171. https:// doi.org/10.1016/j.toxlet.2012.03.800
Liu M, Gao R, Meng Q et al (2014) Toxic effects of maternal zearalenone exposure on intestinal oxidative stress, barrier function, immunological and morphological changes in rats. PLoS ONE 9:e106412. https://doi.org/10.1371/journal.pone.0106412

Liu M, Cheng C, Li X et al (2020) Luteolin alleviates ochratoxin A induced oxidative stress by regulating Nrf2 and HIF-1 $\alpha$ pathways in NRK-52E rat kidney cells. Food Chem Toxicol 141:111436. https://doi.org/10.1016/j.fct.2020.111436

Loboda A, Stachurska A, Podkalicka P et al (2017a) Effect of heme oxygenase-1 on ochratoxin A-induced nephrotoxicity in mice. Int J Biochem Cell Biol 84:46-57. https://doi.org/10.1016/j.bioce 1.2017.01.003

Loboda A, Stachurska A, Sobczak M et al (2017b) Nrf2 deficiency exacerbates ochratoxin A-induced toxicity in vitro and in vivo. Toxicology 389:42-52. https://doi.org/10.1016/j.tox.2017.07.004

Long M, Yang S-H, Han J-X et al (2016) The protective effect of grapeseed proanthocyanidin extract on oxidative damage induced by zearalenone in kunming mice liver. Int J Mol Sci 17:808. https ://doi.org/10.3390/ijms17060808

Long M, Yang S-H, Shi W et al (2017) Protective effect of proanthocyanidin on mice Sertoli cell apoptosis induced by zearalenone via the Nrf2/ARE signalling pathway. Environ Sci Pollut Res 24:26724-26733. https://doi.org/10.1007/s11356-017-0123-y

Malir F, Ostry V, Pfohl-Leszkowicz A, Novotna E (2013) Ochratoxin A: developmental and reproductive toxicity-an overview. Birth Defects Res Part B Dev Reprod Toxicol 98:493-502. https://doi. org/10.1002/bdrb.21091

Maresca M, Mahfoud R, Garmy N, Fantini J (2002) The mycotoxin deoxynivalenol affects nutrient absorption in human intestinal epithelial cells. J Nutr 132:2723-2731. https://doi.org/10.1093/ jn/132.9.2723

Marin S, Ramos AJ, Cano-Sancho G, Sanchis V (2013) Mycotoxins: occurrence, toxicology, and exposure assessment. Food Chem Toxicol 60:218-237

Marin-Kuan M, Nestler S, Verguet C et al (2006) A toxicogenomics approach to identify new plausible epigenetic mechanisms of ochratoxin A carcinogenicity in rat. Toxicol Sci 89:120-134. https://doi.org/10.1093/toxsci/kfj017

Marin-Kuan M, Ehrlich V, Delatour T et al (2011) Evidence for a role of oxidative stress in the carcinogenicity of ochratoxin A. J Toxicol 2011:645361. https://doi.org/10.1155/2011/645361

McCormick SP, Stanley AM, Stover NA, Alexander NJ (2011) Trichothecenes: from simple to complex mycotoxins. Toxins (Basel) 3:802-814

McMahon M, Itoh K, Yamamoto M et al (2001) The Cap 'n'Collar basic leucine zipper transcription factor Nrf2 (NF-E2 p45-related factor 2) controls both constitutive and inducible expression of intestinal detoxification and glutathione biosynthetic enzymes. Cancer Res 61:3299-3307

Meissonnier GM, Pinton P, Laffitte J et al (2008) Immunotoxicity of aflatoxin B1: impairment of the cell-mediated response to vaccine antigen and modulation of cytokine expression. Toxicol Appl Pharmacol 231:142-149. https://doi.org/10.1016/J. TAAP.2008.04.004

Miao W, Hu L, Scrivens PJ, Batist G (2005) Transcriptional regulation of NF-E2 p45-related factor (Nrf2) expression by the aryl hydrocarbon receptor-xenobiotic response element signaling pathway: direct cross-talk between phase I and II drug-metabolizing enzymes. J Biol Chem 280:20340-20348. https://doi. org/10.1074/jbc.M412081200

Mishra S, Dwivedi PD, Pandey HP, Das M (2014) Role of oxidative stress in deoxynivalenol induced toxicity. Food Chem Toxicol 72:20-29

Mishra S, Tewari P, Chaudhari BP et al (2016) Deoxynivalenol induced mouse skin tumor initiation: elucidation of molecular 
mechanisms in human $\mathrm{HaCaT}$ keratinocytes. Int $\mathrm{J}$ Cancer 139:2033-2046. https://doi.org/10.1002/ijc.30260

Motohashi H, O'Connor T, Katsuoka F et al (2002) Integration and diversity of the regulatory network composed of Maf and CNC families of transcription factors. Gene 294:1-12. https://doi. org/10.1016/S0378-1119(02)00788-6

Muhammad I, Wang X, Li S et al (2018) Curcumin confers hepatoprotection against AFB 1 -induced toxicity via activating autophagy and ameliorating inflammation involving Nrf2/HO-1 signaling pathway. Mol Biol Rep 45:1775-1785. https://doi.org/10.1007/ s11033-018-4323-4

Mungenast F, Thalhammer T (2014) Estrogen biosynthesis and action in ovarian cancer. Front Endocrinol (Lausanne) 5:192. https:// doi.org/10.3389/fendo.2014.00192

Nakajima M, Tabata S, Akiyama H et al (2004) Occurrence of aflatoxin M1 in domestic milk in Japan during the winter season. Food Addit Contam 21:472-478. https://doi.org/10.1080/0265203041 0001677817

Nam LB, Keum YS (2019) Binding partners of Nrf2: functions and regulatory mechanisms. Arch Biochem Biophys 678:108184

Peters LP, Teel RW (2003) Effect of high sucrose diet on liver enzyme content and activity and aflatoxin B1-induced mutagenesis. In Vivo 17:205-210

Pinton P, Oswald I (2014) Effect of deoxynivalenol and other type B trichothecenes on the intestine: a review. Toxins (Basel) 6:16151643. https://doi.org/10.3390/toxins6051615

Raghubeer S, Nagiah S, Chuturgoon AA (2017) Acute ochratoxin A exposure induces inflammation and apoptosis in human embryonic kidney (HEK293) cells. Toxicon 137:48-53. https://doi. org/10.1016/j.toxicon.2017.07.013

Rahal A, Kumar A, Singh V et al (2014) Oxidative stress, prooxidants, and antioxidants: the interplay. Biomed Res Int 2014:761264

Rajput SA, Sun L, Zhang NY et al (2019) Grape seed proanthocyanidin extract alleviates aflatoxinb 1-induced immunotoxicity and oxidative stress via modulation of NF- $\mathrm{KB}$ and Nrf2 signaling pathways in broilers. Toxins (Basel). https://doi.org/10.3390/ toxins11010023

Ramyaa P, Padma VV (2013) Ochratoxin-induced toxicity, oxidative stress and apoptosis ameliorated by quercetin-modulation by Nrf2. Food Chem Toxicol 62:205-216. https://doi.org/10.1016/j. fct.2013.08.048

Ramyaa P, Krishnaswamy R, Padma VV (2014) Quercetin modulates OTA-induced oxidative stress and redox signalling in HepG2 cells-up regulation of $\mathrm{Nrf} 2$ expression and down regulation of NF- $\kappa$ B and COX-2. Biochim Biophys Acta 1840:681-692. https ://doi.org/10.1016/j.bbagen.2013.10.024

Rotimi OA, Rotimi SO, Goodrich JM et al (2019) Time-course effects of acute aflatoxin B1 exposure on hepatic mitochondrial lipids and oxidative stress in rats. Front Pharmacol. https://doi. org/10.3389/fphar.2019.00467

Rushworth SA, Zaitseva L, Murray MY et al (2012) The high Nrf2 expression in human acute myeloid leukemia is driven by NF- $\mathrm{KB}$ and underlies its chemo-resistance. Blood 120:5188-5198. https ://doi.org/10.1182/blood-2012-04-422121

Schuhmacher-Wolz U, Heine K, Schneider K (2017) Report on toxicity data on trichothecene mycotoxins HT-2 and T-2 toxins. EFSA Support Publ. https://doi.org/10.2903/sp.efsa.2010.en-65

Schwartz-Zimmermann HE, Binder SB, Hametner C et al (2019) Metabolism of nivalenol and nivalenol-3-glucoside in rats. Toxicol Lett 306:43-52. https://doi.org/10.1016/j.toxlet.2019.02.006

Shi D, Liao S, Guo S et al (2015) Protective effects of selenium on aflatoxin B1-induced mitochondrial permeability transition, DNA damage, and histological alterations in duckling liver. Biol Trace Elem Res 163:162-168. https://doi.org/10.1007/s1201 $1-014-0189-\mathrm{Z}$
Shin HS, Lee HJ, Pyo MC et al (2019) Ochratoxin A-induced hepatotoxicity through phase I and phase II reactions regulated by AhR in liver cells. Toxins (Basel) 11:377. https://doi.org/10.3390/ toxins 11070377

Sobrova P, Adam V, Vasatkova A et al (2010) Deoxynivalenol and its toxicity. Interdiscip Toxicol 3:94-99

Solcan C, Timofte D, Floristean V et al (2013) Ultrastructural lesions and immunohistochemical analysis of Bcl-2 protein expression in the kidney of chickens with experimental ochratoxicosis. Acta Vet Hung 61:344-353. https://doi.org/10.1556/AVet.2013.021

Sporn MB, Liby KT (2012) Nrf2 and cancer: the good, the bad and the importance of context. Nat Rev Cancer 12:564-571. https://doi. org/10.1038/nrc3278

Stachurska A, Ciesla M, Kozakowska M et al (2013) Cross-talk between microRNAs, nuclear factor E2-related factor 2, and heme oxygenase- 1 in ochratoxin A-induced toxic effects in renal proximal tubular epithelial cells. Mol Nutr Food Res 57:504515. https://doi.org/10.1002/mnfr.201200456

Stettler PM, Sengstag C (2001) Liver carcinogen aflatoxin B1 as an inducer of mitotic recombination in a human cell line. Mol Carcinog 31:125-138. https://doi.org/10.1002/mc.1047

Su C, Hu Y, Gao D et al (2018) Occurrence of toxigenic fungi and mycotoxins on root herbs from Chinese markets. J Food Prot 81:754-761. https://doi.org/10.4315/0362-028X.JFP-17-405

Sugita-Konishi Y, Park BJ, Kobayashi-Hattori K et al (2006) Effect of cooking process on the deoxynivalenol content and its subsequent cytotoxicity in wheat products. Biosci Biotechnol Biochem 70:1764-1768. https://doi.org/10.1271/bbb.50571

Suzuki T, Yamamoto M (2015) Molecular basis of the Keap1-Nrf2 system. Free Radic Biol Med 88:93-100. https://doi.org/10.1016/j. freeradbiomed.2015.06.006

Taguchi K, Takaku M, Egner PA et al (2016) Generation of a new model rat: Nrf2 knockout rats are sensitive to aflatoxin B1 toxicity. Toxicol Sci 152:40-52. https://doi.org/10.1093/toxsci/kfw06 5

Tao Y, Xie S, Xu F et al (2018) Ochratoxin A: toxicity, oxidative stress and metabolism. Food Chem Toxicol 112:320-331

Theumer MG, Cánepa MC, López AG et al (2010) Subchronic mycotoxicoses in Wistar rats: assessment of the in vivo and in vitro genotoxicity induced by fumonisins and aflatoxin B1, and oxidative stress biomarkers status. Toxicology 268:104-110. https:// doi.org/10.1016/j.tox.2009.12.007

Toman J, Ostry V, Grosse Y et al (2018) Occurrence of ochratoxin A in Astragalus propinquus root and its transfer to decoction. Mycotoxin Res 34:223-227. https://doi.org/10.1007/s1255 0-018-0317-2

Tonelli C, Chio IIC, Tuveson DA (2018) Transcriptional regulation by Nrf2. Antioxid Redox Signal 29:1727-1745. https://doi. org/10.1089/ars.2017.7342

Tong KI, Katoh Y, Kusunoki H et al (2006) Keap1 recruits Neh2 through binding to ETGE and DLG motifs: characterization of the two-site molecular recognition model. Mol Cell Biol 26:28872900. https://doi.org/10.1128/MCB.26.8.2887-2900.2006

Trucksess MW, Stoloff L, Young K et al (1983) Aflatoxicol and aflatoxins B1 and M1 in eggs and tissues of laying hens consuming aflatoxin-contaminated feed. Poult Sci 62:2176-2182. https://doi. org/10.3382/ps.0622176

Ülger TG, Uçar A, Çakıroğlu FP, Yilmaz S (2020) Genotoxic effects of mycotoxins. Toxicon 185:104-113

Urbanek KA, Habrowska-Górczyńska DE, Kowalska K et al (2018) Deoxynivalenol as potential modulator of human steroidogenesis. J Appl Toxicol 38:1450-1459. https://doi.org/10.1002/jat.3623

Veprikova Z, Zachariasova M, Dzuman Z et al (2015) Mycotoxins in plant-based dietary supplements: hidden health risk for 
consumers. J Agric Food Chem 63:6633-6643. https://doi. org/10.1021/acs.jafc.5b02105

Vipin AV, Raksha Rao K, Kurrey N et al (2017) Protective effects of phenolics rich extract of ginger against aflatoxin B1-induced oxidative stress and hepatotoxicity. Biomed Pharmacother 91:415424. https://doi.org/10.1016/j.biopha.2017.04.107

Wang H, Liu K, Geng M et al (2013) RXR $\alpha$ inhibits the Nrf2ARE signaling pathway through a direct interaction with the Neh7 domain of Nrf2. Cancer Res 73:3097-3108. https://doi. org/10.1158/0008-5472.CAN-12-3386

Wang W-J, Xu Z-L, Yu C, Xu X-H (2017) Effects of aflatoxin B1 on mitochondrial respiration, ROS generation and apoptosis in broiler cardiomyocytes. Anim Sci J 88:1561-1568. https://doi. org/10.1111/asj.12796

Wang H, Muhammad I, Li W et al (2018) Sensitivity of Arbor Acres broilers and chemoprevention of aflatoxin B1-induced liver injury by curcumin, a natural potent inducer of phase-II enzymes and Nrf2. Environ Toxicol Pharmacol 59:94-104. https://doi. org/10.1016/j.etap.2018.03.003

Wang YL, Zhou XQ, Jiang WD et al (2019) Effects of dietary zearalenone on oxidative stress, cell apoptosis, and tight junction in the intestine of juvenile grass carp (Ctenopharyngodon idella). Toxins (Basel). https://doi.org/10.3390/toxins11060333

Wangikar PB, Dwivedi P, Sinha N et al (2005) Teratogenic effects in rabbits of simultaneous exposure to ochratoxin $\mathrm{A}$ and aflatoxin B1 with special reference to microscopic effects. Toxicology 215:37-47. https://doi.org/10.1016/J.TOX.2005.06.022

Wen J, Mu P, Deng Y (2016) Mycotoxins: cytotoxicity and biotransformation in animal cells. Toxicol Res (Camb) 5:377-387

Wolzak A, Pearson AM, Coleman TH et al (1985) Aflatoxin deposition and clearance in the eggs of laying hens. Food Chem Toxicol 23:1057-1061. https://doi.org/10.1016/0278-6915(85)90052-3

Wu Q, Dohnal V, Huang L et al (2011) Metabolic pathways of ochratoxin A. Curr Drug Metab 12:1-10. https://doi. org/10.2174/138920011794520026

Wu Q, Wang X, Nepovimova E et al (2017) Trichothecenes: immunomodulatory effects, mechanisms, and anti-cancer potential. Arch Toxicol 91:3737-3785

Xu Q, Shi W, Lv P et al (2020) Critical role of caveolin-1 in aflatoxin B1-induced hepatotoxicity via the regulation of oxidation and autophagy. Cell Death Dis. https://doi.org/10.1038/s4141 9-019-2197-6

Yang D, Jiang X, Sun J et al (2018) Toxic effects of zearalenone on gametogenesis and embryonic development: a molecular point of review. Food Chem Toxicol 119:24-30. https://doi.org/10.1016/j. fct.2018.06.003

Yang J, Zhu C, Ye J et al (2019) Protection of porcine intestinal-epithelial cells from deoxynivalenol-induced damage by resveratrol via the Nrf2 signaling pathway. J Agric Food Chem 67:1726-1735. https://doi.org/10.1021/acs.jafc.8b03662

Yang C, Song G, Lim W (2020) Effects of mycotoxin-contaminated feed on farm animals. J Hazard Mater 389:122087

Yoon JE, Lee KY, Seok JS et al (2019) Zearalenone induces endoplasmic reticulum stress and modulates the expression of phase I/II enzymes in human liver cells. Toxins (Basel) 12:2. https://doi. org/10.3390/toxins 12010002

Yu M, Chen L, Peng Z et al (2017a) Mechanism of deoxynivalenol effects on the reproductive system and fetus malformation: current status and future challenges. Toxicol Vitr 41:150-158. https ://doi.org/10.1016/j.tiv.2017.02.011
Yu M, Chen L, Peng Z et al (2017b) Embryotoxicity caused by DONinduced oxidative stress mediated by $\mathrm{Nrf} / \mathrm{HO}-1$ pathway. Toxins (Basel). https://doi.org/10.3390/toxins9060188

Yu K, Zhang J, Cao Z et al (2018a) Lycopene attenuates AFB1-induced renal injury with the activation of the Nrf2 antioxidant signaling pathway in mice. Food Funct 9:6427-6434. https://doi. org/10.1039/c8fo01301b

Yu M, Wei Z-Y, Xu Z-H et al (2018b) Oxidative damage and Nrf2 translocation induced by toxicities of deoxynivalenol on the placental and embryo on gestation day $12.5 \mathrm{~d}$ and $18.5 \mathrm{~d}$. Toxins (Basel) 10:370. https://doi.org/10.3390/toxins10090370

Yu M, Peng Z, Liao Y et al (2019) Deoxynivalenol-induced oxidative stress and Nrf2 translocation in maternal liver on gestation day $12.5 \mathrm{~d}$ and $18.5 \mathrm{~d}$. Toxicon 161:17-22. https://doi.org/10.1016/j. toxicon.2019.02.018

Zha A, Liao P, Tan B et al (2020a) Dietary baicalin zinc supplementation alleviates oxidative stress and enhances nutrition absorption in deoxynivalenol challenged pigs. Curr Drug Metab. https://doi. org/10.2174/1389200221666200302124102

Zha A, Yuan D, Cui Z et al (2020b) The evaluation of the antioxidant and intestinal protective effects of baicalin-copper in deoxynivalenol-challenged piglets. Oxid Med Cell Longev. https://doi. org/10.1155/2020/5363546

Zhai SS, Ruan D, Zhu YW et al (2020) Protective effect of curcumin on ochratoxin A-induced liver oxidative injury in duck is mediated by modulating lipid metabolism and the intestinal microbiota. Poult Sci 99:1124-1134. https://doi.org/10.1016/j. psj.2019.10.041

Zhang N-Y, Qi M, Zhao L et al (2016) Curcumin prevents aflatoxin B1 hepatoxicity by inhibition of cytochrome $\mathrm{P} 450$ isozymes in chick liver. Toxins (Basel). https://doi.org/10.3390/TOXINS8110327

Zhang R-Q, Sun X-F, Wu R-Y et al (2018a) Zearalenone exposure elevated the expression of tumorigenesis genes in mouse ovarian granulosa cells. Toxicol Appl Pharmacol 356:191-203. https:// doi.org/10.1016/j.taap.2018.08.013

Zhang X, Wang Y, Velkov T et al (2018b) T-2 toxin-induced toxicity in neuroblastoma-2a cells involves the generation of reactive oxygen, mitochondrial dysfunction and inhibition of $\mathrm{Nrf} 2 /$ HO-1 pathway. Food Chem Toxicol 114:88-97. https://doi. org/10.1016/j.fct.2018.02.010

Zheng W, Wang B, Li X et al (2018) Zearalenone promotes cell proliferation or causes cell death? Toxins (Basel) 10:184

Zhou H-R, Islam Z, Pestka JJ (2003) Rapid, sequential activation of mitogen-activated protein kinases and transcription factors precedes proinflammatory cytokine mRNA expression in spleens of mice exposed to the trichothecene vomitoxin. Toxicol Sci 72:130-142. https://doi.org/10.1093/toxsci/kfg006

Zhou Y, Jin Y, Yu H et al (2019) Resveratrol inhibits aflatoxin B1-induced oxidative stress and apoptosis in bovine mammary epithelial cells and is involved the Nrf2 signaling pathway. Toxicon 164:10-15. https://doi.org/10.1016/j.toxicon.2019.03.022

Publisher's Note Springer Nature remains neutral with regard to jurisdictional claims in published maps and institutional affiliations. 